them. We can assert confidently that in the environment of the University of Sheffield Field Laboratories this particular treatment is completely ineffective.

Much earlier experiments, made for other reasons, in which spontaneous and transplented tumours were injected intratumorally with various concentrations of commercial hydrogen peroxide at intervals from an early stage of growth, were all essentially negative.

Holman makes no reference to the behaviour of his tumour when implanted into control untreated rats. From our own experience we know that even normally highly transplantable tumours occasionally pass through phases when the incidence of natural tumour regression is substantial. In view of this we feel that the 'cures' obtained by Holman may have been, in fact, natural tumour regressions.

H. N. GREEN

J. W. WestroP

Cancer Research Unit,

University of Sheffield. Dec. 5.

${ }^{1}$ Holman, R. A., Nature, 179, 1033 (1957)

\section{Development of Eggs before the Final Moult in Pratylenchus}

Among nematodes separated from soil about the roots of Grenache vines in February 1957 were females of Pratylenchus which carried eggs at their tails, outside the body but within a partly cast cuticle. Six specimens were recovered from a few pounds of soil. The life-cycle of a typical Pratylenchus ${ }^{1}$ includes four moults from egg to adult, the first moult occurring in the egg, where the second-stage larva may be distinguished by the appearance of a well-defined buccal spear. In each of these specimens the egg contained a clearly differentiated second-stage larva. The cuticle of the nematode was detached at the head region and at the rear of the body from a point anterior to the vulva. Many normal specimens of Pratylenchus were also present, and one apparently larval female carried an egg with a second-stage larva in the oviduct.

Three of the specimens with eggs at the tail were kept in a dish of water. Two died within a few days, but the third emerged about half-way from the old cuticle before death.

Ten similar specimens were recovered from samples taken at the same site about a month later. One of these carried two fully differentiated eggs within the old cuticle. Two specimens showed no differentiation in the eggs-just a number of cells. All showed displacement of the cepholic cap, which indicated commencement of moulting. One specimen which started to emerge from the old cuticle was transferred to a slide, and under the slight pressure of the cover-glass the nematode completed the moult in a few minutes, surviving for about a week on the slide. The egg with cast cuticle was retained for more than a fortnight in water, but did not hatch.

It appears that females of this species may, in certain circumstances, produce eggs before the final moult takes place. Eggs thus produced cannot be laid in the normal way as there is no adequate aperture at the vulva for them to pass the larval cuticle. The egge are retained in the body, and may undergo considerable development, until the final

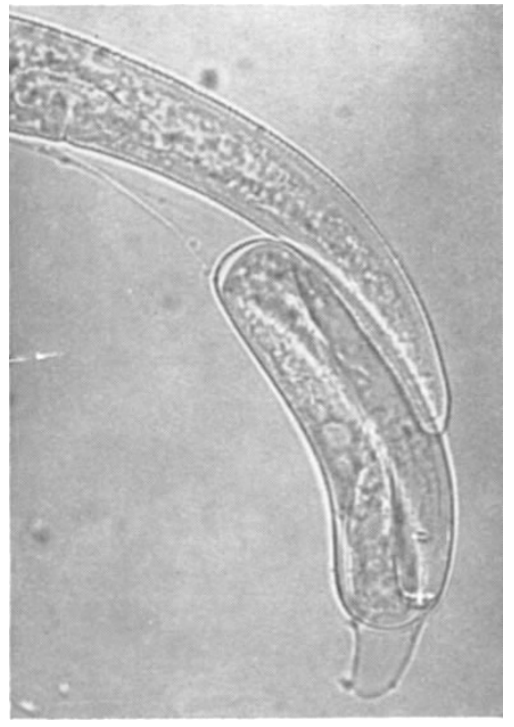

Fig. 1. Tail of Pratylenchus minyus showing egg retained by partly cast cuticle

moult commences. When the cuticle begins to separate from the body, the egg can pass the vulva, and finds its way to the tail within the cuticular sac. Completion of moulting releases the egg. Although the one egg obtained free from these specimens did not hatch, these eggs may normally be viable. However, the fact that so many of the eggs observed were at an advanced stage of development suggests perhaps that hatching has been inhibited.

Little is known of the mechanisms which control development in plant parasitic nematodes. It cannot be judged whether development of the reproductive system has been accelerated, or whether moulting has been retarded in these specimens, but the two processes are obviously not interdependent. No treatment other than normal vineyard practice has been applied to the area from which these nematodes were taken.

The species concerned is morphologically similar to Pratylenchus minyus Sher and Allen ${ }^{2}$, but no males have been found.

\section{R. SAUER}

Commonwealth Scientific and

Industrial Research Organization,

Commonwealth Research Station, Merbein, Victoria.

1 Jensen, H. J., Ph.D. dissertation, University of California Library (1950)

${ }^{2}$ Sher, S. A., and Allen, M. W., Univ. Calif. Pub. Zool., 57, 441 (1953).

\section{Light Reactions of Littoral Gastropods}

Molluscan behaviour has attracted the attention of many workers, and the literature contains several references to the homing ability and direction finding in various gastropods'. Light is acknowledged as an important factor in such mechanisms in numerous invertebrates, and recently the plane of polarization of light has been shown to be an operative factor in the orientation of Eupagurus bernhardus ${ }^{2}$, the xiphosuran Limulus ${ }^{3}$, some hymenopterous and lepidopterous larvæ4, and various insects ${ }^{5}$. 